\title{
Chapter 9 The Cultural Landscape of Three-Dimensional Imaging
}

\author{
Sean F. Johnston \\ University of Glasgow, UK
}

\section{Introduction}

This chapter explores the cultural contexts in which three-dimensional imaging has been developed, disseminated and used. It surveys the diverse technologies and intellectual domains that have contributed to spatial imaging, and argues that it is an important example of an interdisciplinary field. Over the past century-and-a-half, specialists from distinct fields have devised explanations and systems for the experience of 3-D imagery. Successive audiences have found these visual experiences compelling, adapting quickly to new technical possibilities and seeking new ones. These complementary interests, and their distinct perspectives, have co-evolved in lock-step. A driver for this evolution is visual culture, which has grown to value and demand the spectacular. As a result, professional and popular engagements with 3-D have had periods of both popularity and indifference, and cultural consensus has proven to be ephemeral.

As the preceding chapters illustrate, the field of 3-D imaging is one that has encouraged a diversity of approaches. Physicists and optical engineers have focused on the properties of light to understand how three-dimensionality can be modelled and reproduced optically. Physiologists have studied binocular vision to reveal how the eyes and brain achieve the miracle of stereopsis. Artists have been intrigued by this curious dimension of imaging that falls between sculpture and painting. And, historical accounts provide a further axis - time - that solidifies these discrete perspectives, placing them in a temporal order that hints at causes and effects.

Each of these perspectives frames the field uniquely, but linking them are the threads of culture. It is generally appreciated that artists and their works flourish or fade in particular cultural environments, but we often overlook the cultural dimensions of science and technology. While scientific attention, for example, may occasionally be prompted by a 'breakthrough' - a sudden revelation triggered by a newly discovered fact -more often than not is inspired by a pre-existing influences. Scientific networks, current topics of discussion and intellectual fashions all play a role in determining where attention is focused and how problems are pursued. Similarly, engineering development may be motivated by identification of a market need, available resources or a particular constellation of skill-sets. The successful marshalling of these factors often requires a particular cultural context. The attitudes and understandings of peers and competitors, purchasers and critics, shape the trajectory of technologies and their social uses.

As this hints, any one of these perspectives - scientific, technological, artistic, economic - may restrict vision, too, in just the way that the Victorian stereoscope provides a sense of reality that is nevertheless unable to view the parts of the scene masked by others.

There are other disciplines, too, that have engaged periodically with the attractions of light and vision. Some of them have had disputed intellectual borders. The link between the eye and brain has both brought together and divided physiologists and psychologists since the turn of the twentieth century (Johnston 2001). The mid-century origins of holography forced together optical specialists and radar engineers, merging the fields of physical optics and communication theory in the process (Johnston, 2006). And the technical subject of imaging has been partitioned through the past century first by the technologies of photographic film and electronic sensors, and later by equally deep analogue-versus-digital divides. 
Such collisions of intellectual worlds are at the heart of three-dimensional imaging. The field straddles disciplines, and this uncomfortable position helps explain why it has periodically inhabited a hinterland. Which experts can provide an authoritative voice, guide its path and predict its future? In practice, 3-D imaging has required a melding of expertise, drawing together knowledge, innovation and forecasting. The field is interdisciplinary: more than the sum of its parts, its successful branches have merged disciplinary insights into shared practice. These ongoing processes provide a rich seam for social scientists and scholars of the humanities to explore.

But beyond professional practices, the culture of 3-D imaging has been shaped by its adopters and nonadopters, too. Popular culture, especially since the invention of photography, has been expressed increasingly as a visual culture. The succession of imaging technologies has revealed the role of visual spectacle, and public appetite for new forms of visual surprise. Photography, graphic arts, cinema and television buffeted and contributed nuances to popular visual culture, and popular uptake (and sometimes rejection) was driven by those currents.

This chapter, then, traces the cultural dimensions - professional, popular, and visual - of threedimensional imaging technologies. In the process, it hints at the integrative vision of cultural studies of imaging, an approach explored elsewhere in greater depth (Johnston, 2015). 3-D imaging and popular culture developed together and shaped each other. Understanding the wider implications of this coevolution is important for riding the succeeding waves of our technological culture.

\section{Background: the role of culture}

Culture is often overlooked in scientific and technical fields, but much less frequently in overtly artistic and creative fields. 3-D imaging involves all of these, and so a comprehensive appreciation of the field demands a universal glue to bind its components together.

Such a glue is cultural studies. The vague term 'culture' incorporates dimensions that seldom are made explicit in some disciplines. These include notions such as collective belief, community values, popular fashion, customs, philosophical or religious convictions, shared aesthetic sensibilities and forms of creative expression such as music and art.

The relevance of such concepts may not always be obvious, but they can enrich understandings of human activities. This may apply as much to disciplinary experts as to members of the wider public. As noted in the Foreword, physicist Stephen Benton suggested that new technologies evolve inexorably, but historians of technology can find many counter-examples. Indeed, three-dimensional imaging technologies, as a class, have had mixed fortunes. Some achieved significant 'market penetration', to use a phrase popular with economists, but others have been dismissed by consumers with scarcely a second glance. Stereoscopes are an example of a highly popular technology for Victorian audiences, but increasingly dismissed by their children and grandchildren. 3-D cinema has periodically mushroomed in popularity, only to decay again within a decade. And, with the growing union between electronics, computing and optics since the 1980s, a variety of sophisticated imaging technologies have enthused their engineering proponents but sometimes made relatively little impact beyond their specialist communities. Virtual reality headsets, for example, were a flash in the pan during the 1990s. Recognising the historical inevitability of 3-D imaging, then, may be more a matter of philosophical confidence or collective belief.

Explaining popular failures can also be susceptible to myopia. Some of them, of course, have clear technical limitations, as noted in the Introduction. Imaging systems that do not provide all the attributes of stereopsis - or, even worse, force them to compete within our visual system - are likely to be found wanting in some circumstances. But the rise and fall of such technologies reveals the shifting interplay between collective judgement and personal experience. For a time, those technologies were appealing, 
seductive, exciting - only to be rejected later when they no longer mapped onto other criteria drawn from prevailing fashions and cultural desires. Such technologies did not, or did not for long, resonate with wider community values. Identifying those values may be difficult to discover or demonstrate, though. For example, we may muse as to whether the decline of virtual reality (VR) systems linked in part to physical isolation from others - making the synthetic experience, even when combined with virtual communication with other real players, too different from the conventions of 1990s daily life. Or was it in part because VR became too closely associated with particular gaming cultures, celebrity endorsers or the palette of products from a particular company? Such potential explanations would require considerable work to investigate, but could inform the evaluations made by the next generation of technology companies seeking to revive or improve upon the concept.

The cultural studies approach, admittedly, has some difficulties from the standpoint of science and technology. Its claims may be difficult to quantify: how do we measure the impact of a new idea, for example? One approach is to measure what can be measured - e.g. the number of stereoscopes sold, or the attendance figures for hologram exhibitions - and to make cautious hypotheses beyond them. An additional method is to exemplify, providing cogent anecdotes that characterize community views or popular attitudes. Often focusing on popular culture - mass media, fashion, new technologies and evolving customs - cultural studies can probe deeper societal structures, or alternatively give a perceptive but unfamiliar characterization of changing ways of life. This discipline-crossing approach can be both fertile and disorienting, encouraging the re-examination of our shared perceptions and beliefs. But some have argued that with its rising popularity has come a shift away from analytical precision to mere entertainment for uncritical audiences (Pihlainen, 2012).

Given these limitations and critical approach, the wide attentions of cultural studies may provide a discordant note in some discussions about technology. A few technologies have become polarized by competing views, e.g. biologists pursuing genetic engineering, and physicists dedicated to nuclear power, on the one hand, versus wary publics on the other. These confrontations illustrate more than merely 'competent' and 'incompetent' positions: they represent jarring cultures with competing philosophies, norms and behaviours. By contrast, the field of 3-D imaging, a collection of disparate interests having a long history of cooperation, can be better understood and further reconciled by attention to the cultural dimension.

\section{Professional cultures}

Making sense of the dynamics of three-dimensional imaging technologies - their invention, improvement, promotion and popularisation - is aided by appreciating the distinct working cultures in which they developed.

As discussed in Chapter 1, 3-D imaging exploded in the mid-nineteenth century as a novel variant of photography. Stereoscopy as a science became dominated by scholars just then becoming differentiated as 'physicists'. They adopted new techniques of visual experimentation to better explore, demonstrate and debate stereoscopic vision (Crary 1990). In some cases they adapted their apparatus into practical viewing devices, exhibited them to wider publics, and promoted applications.

Within a decade, this rapidly emerging technology was shared between scientists and commercial photographers. Photographers themselves included a spectrum of expertise from chemists (dabbling empirically in a proliferating variety of exposure and development processes) to mechanical inventors (devising ganged shutters, clever camera bodies and shifting tripods) to optical scientists (calculating improved lens designs and stereoscopic viewers). These cultures rapidly diverged and stabilized. They stratified expertise by defining the criteria that united the different clans of practitioners. 
Professional standards clarified their art. Through organisations such as the Royal Photographic Society and periodicals such as The Photographic Journal (both founded under different names in 1853), photography became more scientific. Recuperated from amateurs and entrepreneurs, these bodies sought to base photographic techniques more explicitly on chemistry and physics. By the end of the century, company research labs were beginning to emerge, professionalising these new working criteria. Zeiss Optical Works in Jena, Germany, employed physicists not merely to design lenses but to probe the theoretical limits of resolution; at chemical companies such as Gaskell-Deacon works in Lancashire, laws of photographic exposure were teased out; new, dedicated corporate labs sprouted, including those founded by British Thomson-Houston (1894), Du Pont de Nemours (USA, 1903), the National Electric Lamp Association ('NELA', USA, 1908) and Eastman Kodak (1912). National laboratories followed the firms, with the Physikalisch-Technische Reichsanstalt (Germany, 1887), the National Physical Laboratory (UK, 1889) and Bureau of Standards (USA, 1901) each setting up optics divisions.

This new clustering of societies, companies and institutions collectively defined the nature of optical science and industry at the turn of the twentieth century. Within each was a distinct mixture of technical expertise. Kodak combined divisions of chemistry, optics and mechanical engineering; NELA was topheavy with physicists and electrical engineers and a smattering of opthalmologists and architects. And scientists at the national laboratories, striving to set standards for 'normal' human vision between the world wars, found themselves uncomfortably often face to face with psychologists (Johnston 2001).

Acknowledging the flavours of expertise, stewing together to cook unique working cultures, can help to explain why some imaging technologies prospered or faltered. Gabriel Lippmann's integral photography, discussed in Chapter 8, is a case in point. Lippmann was the doyen of scientific photography. His scheme for three-dimensional imaging, like his concept of interference colour photography (a precursor to what eventually became holography), employed sophisticated physics and careful experimental verifications. Yet his two contributions to the field of photography made little sustained impact on his contemporaries. His peers were impressed by his scientific insights, but did relatively little to extend them either theoretically or experimentally. Contemporary French physicists criticized Lippmann's arbitrariness in adopting chemical processes; for these technical experts, his interferential photography (Lippmann 1891) was neither, as supporters claimed, 'direct photography', 'natural colour' nor 'objective colour reproduction'. Instead of being an absolute scientific technique, it was just as capricious and subjective as previous methods of generating colour photographs were (Mitchell 2012). The seeming scientific rigour, they suggested, was in fact a fudge.

\section{Popular culture and spectacular imagery}

Popular culture is at least as important in assessing new technologies as professional cultures are. In the case of Gabriel Lippmann's photography, expert criticisms about theoretical elegance were relatively unimportant; what mattered more was popular judgements about the practicality of Lippmann's colour technique. 'Practicality' had a shifting definition, though. Lippmann's system, while eventually meriting the 1908 Nobel Prize, failed to satisfy the reasonable expectations of contemporary culture. His emulsions were much slower than panchromatic emulsions of the time, meaning that still-lifes or posed portraits of Daguerrean rigour were the only option for Lippmann photographic enthusiasts. These were not technical objections alone; after all, photographic processes have always constrained the nature of the images they can record. Fifty years earlier, Louis Daguerre's results had unlocked doors, exciting audiences having few expectations and liberating them to explore the novel applications of photographs. What made colour processes, and especially Lippmann's technique, unacceptable was that they mapped so poorly onto contemporary cultural requirements. In an age being transformed by mechanization and speed, timeexposures were no longer a meaningful representation of reality. 
The rising scientific culture was paralleled by a growing popular engagement with imaging technologies. The rise of photography provided a cultural framework for stereoscopes, and these in turn underlay the popular understandings that assessed 3-D motion pictures and holograms decades later. At least four routes contributed to the diffusion: the incorporation of photographs into social life and the home; the uptake of amateur photography; the availability of new technical processes for image reproduction and the consequent expansion of imaging in print media; and, a proliferating variety of images for mass consumption. Together, these contributions promoted a rising visual literacy and appetite for novelty among wider publics.

Over the first fifty years after its invention, the consumption of photographic imagery took place principally in the home. Audiences quickly grew accustomed to the new portraiture and incorporated it into their home lives. The late Victorian parlour increasingly displayed framed family photographs. The rise of the stereoscope, however, transformed the consumption of photographic images. The scientific experiments of the late 1830s blossomed with the Great Exhibition of 1851 and commercial availability soon afterward. The stereoscope successfully combined the appeal of viewing family photographs at home with other forms of home entertainment and education. It broadened the content and transformed the parlour into an outward-looking social environment. A stereo slide collection was akin to a piano or small library; it could be shared to enliven small gatherings, but could also provide private entertainment and even independent study of a newly visible wide world. This novel visual experience shaped viewers' engagement with photography during the second half of the nineteenth century.

The flip side of these expanding cultural uses was that the viewing public became increasingly sensitized to new visual surprises. This was an age of visual tricks, when 'scientific optics' could reveal baffling visual effects for entertainment; the creators and promoters of stereoscopes also introduced optical toys such as the kaleidoscope, zoetrope and magic lantern. The appeal of visual surprise was also behind the international commercial market for stereograms. The unfamiliarity of far-away places proved captivating, and photographers discovered an exploding international market for their easily-transported views. Stereogram scenes also relied increasingly upon episodic novelty and wonder. Current events were a fertile source of views; ceremonies such as the Japanese emperor's birthday, for instance, could reveal unfamiliar cultural practices to curious viewers. Technological accidents such as train wrecks became an important sub-genre (Figure 1a). The aftermath of conflagrations, earthquakes and typhoons proved popular, and military scenes had a similar vicarious fascination (Figure 1b). Such visual interests long preceded the public experiences of the Vietnam War through television, and the rise of internet sites devoted to the schadenfreude of unpublishable graphic images.
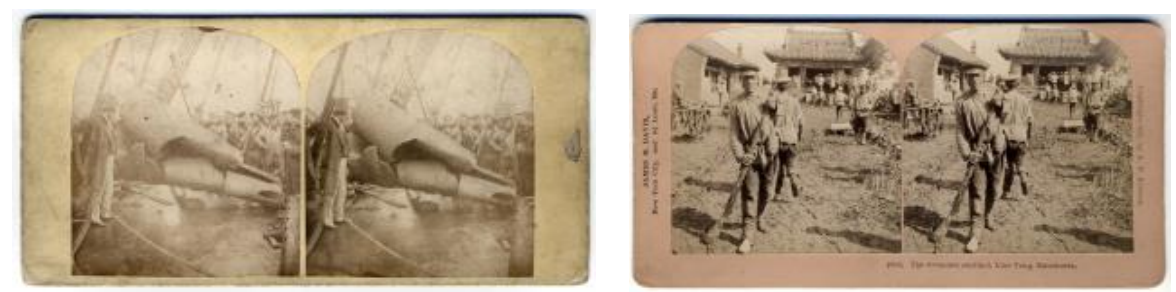

[Figure 1: (a) 'The Great Eastern in the stereoscope', London Stereoscope Co., c1859-60; (b) 'The wounded sentinel, Manchuria', W. B. Kilburn, 1905.]

Thus spectacle, surprise and satiation combined in stereoscope views. But a crucial and unique feature was the visual depth of the images themselves: their stereoscopic nature was central to their appeal. A comparable popular uptake had not occurred with regular photographs (and would not happen until cheap reproduction became possible). 
Viewers quickly discovered that stereoscopy was immersive. It required the viewer to look into a device that closed off the field of view and replaced their visual world with a new, detailed and deep one. The most popular versions, constructed from steam-shaped wood veneers, form-fitted the face like a scuba mask and focused attention just as the blinkers of a carriage horse did. Users could examine and savour fascinating scenes with a directed attention and a sense of safe and private - almost voyeuristic participation. And even monochrome or hand-tinted stereo views provided a sense of realism superior to other visual media. As Oliver Wendell Holmes described,

The first effect of looking at a good photograph through the stereoscope is a surprise such as no painting ever produced. The mind feels its way into the very depths of the picture. The scraggy branches of a tree in the foreground run out at us as if they would scratch our eyes out. The elbow of a figure stands forth so as to make us almost uncomfortable. Then there is such a frightful amount of detail, that we have the same sense of infinite complexity which Nature gives us (Holmes, 1859).

The experience could be sublime, enthralling and visceral. Views of mountain-scapes, tall buildings and monuments employed that perspective to impress upon viewers a sense of height or grand vistas. Given the vividness and depth of imagery, a market for erotic images developed steadily. More subtly, threedimensionality encouraged depth of interpretation as the eye roamed from foreground details to their wider contexts.

Stereoscopes, then, offered rich opportunities for visual entertainment and education. Their popularity was strong from the 1850s up to the turn of the century as new content drew in new audiences. The last technological innovation to sustain markets was the introduction of printing processes that could reproduce photographic images, offering lower costs and the introduction of reliable colour. The declining appeal of stereoscopes during the Edwardian era, however, illustrates the factors behind declining popular appeal. Visual interest proved difficult to sustain into the twentieth century as new media challenged the supremacy of the stereoscope.

Just as chemical imaging was being made more scientifically rigorous, practical as an engineering art and appealing as a popular medium, mechanical imaging, too, was being improved systematically. Since the European adoption of movable type in the fifteenth century, printed images had relied on wood-cut, engraved metal or, by the eighteenth century, etched stone surfaces (lithographs). The new halftone screen process, perfected by the early 1890 s, allowed publishers to print photographic images having a full range of grey tones on the same sheet as set type. Just as importantly, the technique mechanized image reproduction. Expert fine engravers were replaced by artisans adopting more readily-mastered skills. The cost and time needed to reproduce images plummeted, and their content moved from artistic to photographic. The invention of the halftone process consequently produced a step-change in public access to photographs. Instead of being limited to a small collection of personal tintype portraits or handmade stereoscope views, fin de siècle audiences could view photographic images in a growing range of newspapers, magazines and cheap stereo views. Print media began a cultural transition towards photographic imagery (Phillips 1995).

Picture periodicals consequently exploded from the turn of the century, offering the consumption of imagery more cheaply and quickly. The falling price of stereo views themselves also arguably made them less appealing. Just as the introduction of encyclopaedias on CD-ROM and later free internet sites devalued the appeal of printed encyclopaedias, cheaply printed stereo views may have made them too ubiquitous, eroding the sense of exclusiveness felt by middle-class audiences two generations earlier. As the cycles of appeal of twenty-first century products reveal, mass markets often begin with elite purchasers and end when everyone can, and does, have one. Competition, too, played a role. Other technologies provided audiences with new pastimes to replace the stereoscope's appeal. By the First 
World War, stereoscopy was no longer exhilarating. Visual thrills required constant stimulation, and the stereoscope had used up its stock of visual surprise and technical innovation.

\section{Extending visual culture}

Combined with inexpensive reproduction in periodicals, photography transformed visual experience for twentieth-century publics. Ideas introduced by a handful of artists spread internationally with unprecedented speed. Among the most influential was Alexander Rodchenko (1891-1956), the seminal creator of artworks, photographs and graphic art in the early Soviet Union. His contributions to photography were arguably his most influential work. Rodchenko and his peers pioneered ideas that were rapidly taken up in graphic arts around the world.

The first seminal idea was Rodchenko's exploration of unusual perspectives. Indeed, his work challenged the turn-of-the-century pictorialist movement, which sought to turn the craft of photography into an art form modelled on the aesthetic principles of drawing and painting. Artistic notions of perspective, composition and portrayal of reflective mood had become central to its practitioners.

In some respects, camera design until the first decade of the twentieth century had also constrained visual ideas. This, too, was a cultural product, not entirely a deterministic effect of the technology itself. Camera designers sought faithful reproduction of conventional scenes, and their criteria were shaped by contemporary art and urban culture. As a result, serious photographers had been materially encumbered and perceptually channelled by large-format, tripod-mounted plate cameras. The unwieldy hardware was designed to reproduce the horizontal view of human eyes and the traditional perspective of paintings. The designs of equipment consequently favoured these conventions. Pointing upwards or downwards at steep angles was discouraged by problems of camera stability for the long exposures typically used and by the difficulty of loading photographic plates and viewing the ground-glass to focus and compose the picture. As a result, good photographic images aimed to be horizontal, well-focused and carefully posed. Stereo slides had surprised viewers with their three-dimensional content but less frequently by their vertiginous perspectives.

Rodchenko, by contrast, adopted compact, hand-held cameras and pointed them in unfamiliar directions. This was both a technological and cultural shift. To gaze sharply upward or downward was (and still is, in some settings) an unusual social act. Familiar to children, it is culturally discouraged for adults, for whom such views may be interpreted as threatening, provocative or naïve. To stare upwards at city high-rise towers is often the mark of a tourist; to peer down from a high vantage point may be labelled as furtive or voyeuristic. And gazing closely at people in public - especially when recorded candidly via a camera for subsequent examination - can be seen as impolite and intimidating. The unconventional pointing of a camera, then, could recover childlike dimensions and fresh perspectives, both visual and social. Rodchenko's photographs defamiliarized imagery. The viewer was challenged to recognize and accommodate the odd perspectives. The result could be liberating, revealing unnoticed details and viewpoints, or even frightening. His graphic technique was a new form of spectacle that forced viewers to appreciate the social and even political dimensions of images. It contrasted the introspective tranquillity of pictorialism with an aggressive celebration of the modern social world. Realistic imagery could now be unnerving and even shocking (Tupitsyn, 1996).

Rodchenko's avant-garde style of spectacular imagery - especially when applied to industrial subjects illustrates historian David Nye's notion of the 'technological sublime' (Nye, 1994). The sublime is an experience that transcends the ordinary, often associated with religious revelation, and characteristically evoking exaltation, wonder and fear. The technological sublime is such an experience instantiated in a modern technology or, indeed, imagery that highlights it. For Victorians, stereoscopes had provided that thrill. Rodchenko's graphic arts stretched visual culture further. 
The second unsettling technique promoted by Rodchenko and his peers - photomontage - used photographs as graphic elements in ways that again challenged three-dimensional perception. Borrowing from Cubist art, the combination of visual elements combined jarring perspectives to confuse viewers' sense of depth and point of view. Their creators argued that, in photomontages, the photograph could shock the viewer much more effectively than artistic creations could, because its documentary quality emphasized the reality and currency of a visual event while emphasizing their unfamiliarity - a quality sensed in earlier stereo views. And like later holograms, the photomontage combined disturbing realism with the jarring perception of multiple perspectives.

The new field of photojournalism embraced these graphic approaches and technological tools. Magazines between the world wars became flooded with images, and cross-talk between them generated increasingly dramatic and breath-taking views that sought to surprise and unsettle their viewers. Soviet magazines such as Kino-Fot (USSR, 1922) and LEF (USSR, 1923) were among the first, quickly followed by Broom (Italy, 1924) and Arbeiter-Illustrierte-Zeitung (AIZ, Germany, 1924). A growing number of topical magazines such as $V u$ (France, 1928), Regards (France, 1932), Life (USA, 1936), Look (USA, 1937) and Picture Post (UK, 1938) further popularized these visual themes. And what had begun as an explicit movement in art and a medium for political education continued in the west to inform photojournalism, advertising and popular culture.

The market for such magazines and visual spectacle expanded rapidly through popular culture. Examples filled wide-circulation magazines aimed consciously at 'everyman' and 'everywoman'. During the 1930s and 1940s, magazine readers were presented with disorienting or surprising photographs, some of which became regular features. The surprise could be elicited not just by viewing the world from unconventional angles, but also by viewing the ultra-small or invisible (Figure 2a). Amateurs were similarly encouraged to add excitement to their photographs by tricks made possible with optical and mechanical tinkering (Figure 2b).

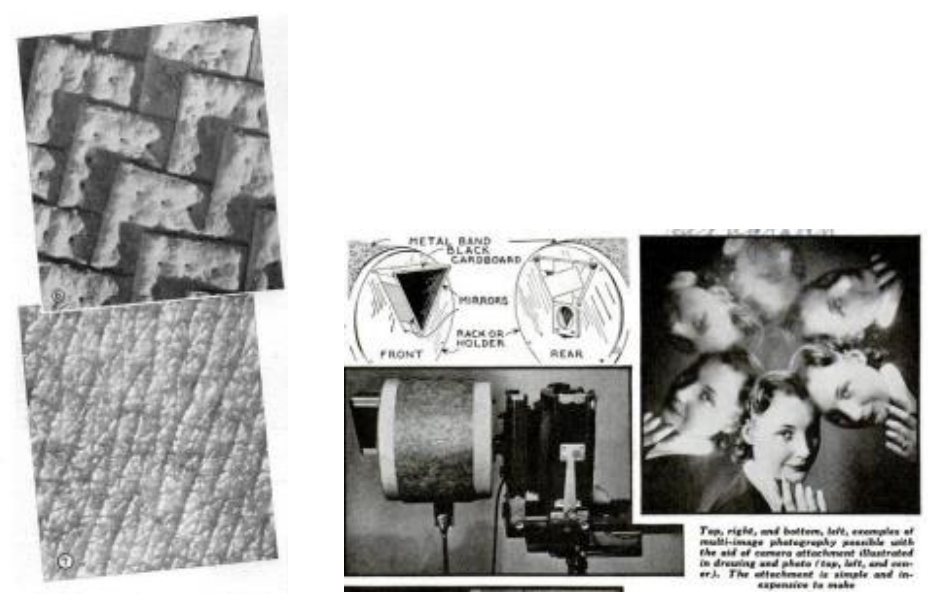

[Figure 2: (a) Disorienting close-up views, a popular genre during the 1930s and 40s (Korth, 1944); (b) kaleidoscopic pictures at home (Uncredited photographer, 1940).]

In a sense, these three levels of spectacular imagery - ranging from early Soviet photographic art as propaganda, to photojournalistic representations of sublime technologies, and finally to amateur close-up photography - were equally radical. They employed bold new perspectives to deconstruct conventions and to instil new political, economic and perceptual orientations, respectively. Audiences that initially were discomfited were ultimately seduced. 
Professional cultures also found themselves adopting the spectacular visuals. Postwar technical magazines employed visual surprise to communicate the power of modernity itself (Figure 3). Illustrations of hightechnology visual sciences also frequently featured, with stories on microscopy, stroboscopes and stereoscopy in science. Indeed, striking images offered an apt analogy for the editorialists' aims:

The Technology Review is designed to be an editorial stereoscope for presenting Science's new world picture in the startling clarity of relief. It goes beyond the mere reporting of science and engineering news in plano; it adds the third dimension of interpretation (Rowlands \& Killian, 1937).

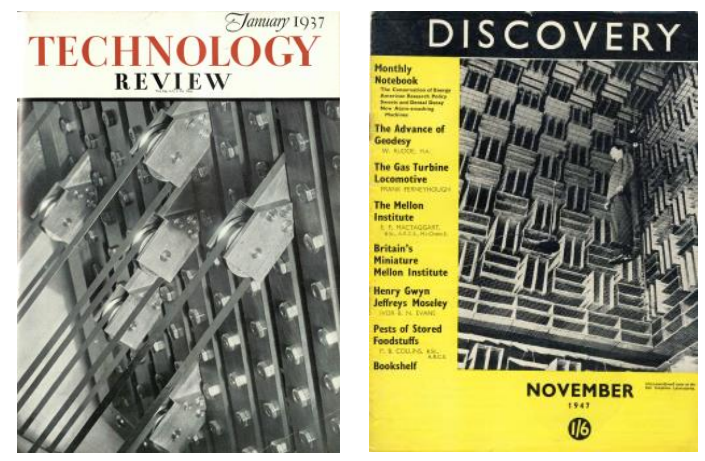

[Figure 3: Technical magazines adopting visual surprise: (a) an MIT analog computer (uncredited photographer, 1937); (b) a Bell Telephone acoustic laboratory (uncredited photographer, 1947).]

Education had been an important theme for the stereoscope from the 1850s, and it sustained it through the early twentieth century: stereo views could tempt students to learn. Visual education was promoted by educationalists during the 1920s, and maps, illustrations, diagrams, graphs, projected images and stereo views were marshalled as their tools; stereo slide publishers aggressively promoted the use of stereoscopes in schools (Bak, 2012). As one teacher argued,

The finest service yet rendered in the schoolroom has been done by the stereograph. The photograph presents but two dimensions. But the stereocamera and the stereoscope work a miracle. They supply the actuality of binocular vision, and the third dimension is presented to the eye in vivid reality. The person who looks through the stereoscope looks upon the real mountain, looks into the depths of the real canyon, looks upon the actual statue, the actual cathedral... It becomes a game to see who can stand and report in good English what he saw, looking through the window of the stereoscope into the reality beyond (Good, 1922). 


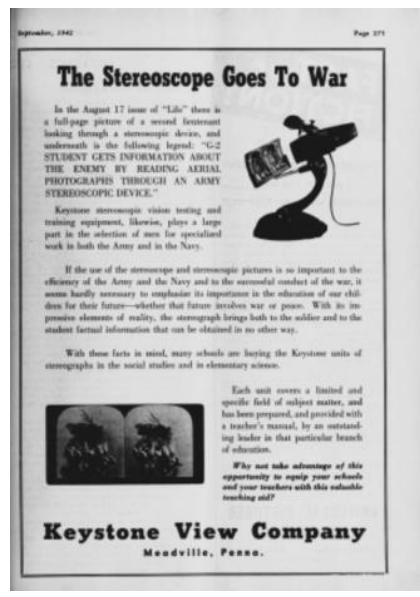

[Figure 4: From students to soldiers: stereoscopes as educational technology (Keystone Company, 1937 and 1942).]

The tactical value of stereo views for wartime education and photo-interpretation were also promoted by stereoscope manufacturers (Figure 4), but children of the 1940s became the principal users of stereoscopes through a revitalized version of the technology. The View-Master, a plastic binocular viewer for stereo view disks that incorporated seven pairs of colour transparencies, was introduced at the New York World's Fair in 1939 and, like the Great Exhibition eighty-eight years earlier, it generated a sales bubble. The vibrant colours, bright images and simple construction made it an appealing children's toy, and parents were reintroduced to stereoscopy as entertainment after a two-generation decline. The todayforgotten visual thrill of seeing bright colour slides - only possible after the marketing of Kodak and Agfa colour films from the late 1930s - was spectacular in just the way that Victorian optical toys, early cinema and Rodchenko's perspectives had been. Combined with stereoscopy, they captured new audiences. A postwar fashion for amateur stereo photography expanded through the early 1950s particularly in the USA. The Stereo Realist camera, introduced in 1947, triggered competition to produce modern stereo cameras and viewers expanded again as it had first done in Europe at the beginning of the century (Figure 5). 

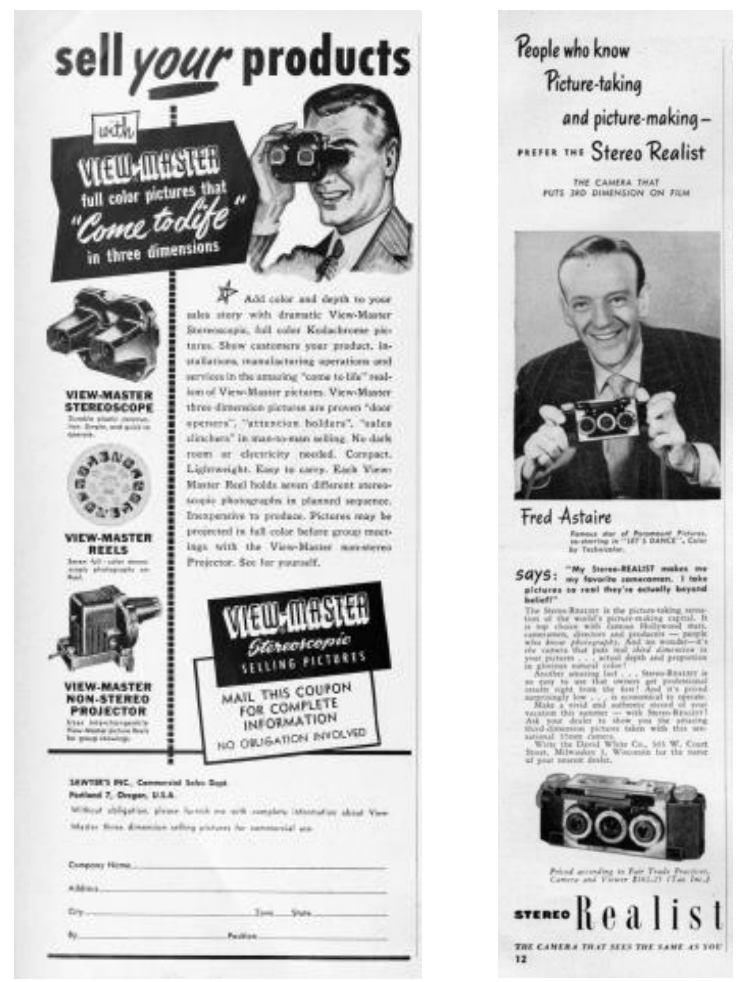

[Figure 5: (a) stereoscopy for merchandising (Sawyer's Inc, 1949); (b): Fred Astaire promotes amateur stereo photography (David White Co, 1950).]

In their own way, motion picture technologies sought to attract audiences by new forms of visual spectacle. Motion itself had proved to be shocking in the earliest public showings. The Lumière brothers' 1896 film of an approaching steam locomotive famously startled audiences unaccustomed to entertainments that threatened to leave the stage. Cinematic innovations focused on providing a more captivating approximation of reality. Sound reproduction, especially when synchronized with the moving image to allow dialogue, transformed the nature of cinema. Colour processes, exhibited experimentally from the turn of the century, sought to transform the monochromatic image into something more lifelike (although the earliest hand-tinted frames could accentuate the visual surprise by showing red fire or unexpected blue below-the-sea views). During the 1930s practical (but relatively expensive) full-colour processes were brought to large audiences, again with the intention of boosting audiences by provoking visual excitement.

Further immersion of viewers within the image could also generate surprise. Widescreen formats were trialled from the 1920s, touted as a new and natural cinematic experience because it more closely mimicked the field of view of two eyes. As film producers sought to compete against the looming threat of television during the 1940s, a variety of wide-screen processes and screen geometries were developed to saturate the audience's field of view, sometimes with the directional cues of two- or multi-channel sound tracks. The increasingly absorbing experience of films such as Walt Disney's Fantasia (1940) could be spectacular, and the more successful films of the period emphasized physical scale and grandeur, effectively recreating the sublime experience. The most ambitious of these technologies was Cinerama in 1952, which relied on three synchronized projectors to illuminate a screen that covered a viewing arc of 146 degrees for audiences of up to 800 .

Motion pictures rehearsed some cultural desires of earlier imaging technologies, and 3-D processes accentuated them further. There had been a significant overlap between early cinema and the parlour 
technology of the stereoscope. Stereoscopic films had been created and exhibited experimentally since the beginning of cinema; indeed, the Lumière Brothers' train had been filmed with two $35 \mathrm{~mm}$ cameras and shown to some audiences via two-colour (anaglyphic) stereo glasses. In 1912, an executive of Selig Polyscope Company, an early motion picture firm, mused about the future for cinema. Instead of being relegated to boardwalk entertainments and make-shift viewing rooms, he suggested, the motion pictures of the future would have colour, sound, immediacy and depth; they would provide a fully natural reproduction of reality amenable to personal use:

The relief attachment... makes the picture stand out from the screen in a bold, natural relief, instead of being flat. It is the same effect, in short, that our brothers of yesterday secured when they looked at the double picture through what was termed a stereoscope (Twist, 1912).

For postwar Hollywood, however, 3D movies promised further spectacle and competitive distancing from increasingly familiar and mundane home entertainments. In the same year that Cinerama was debuted, an unexpectedly popular film, Bwana Devil, launched a craze in American movie theatres for stereoscopic movies. In 1953 over thirty 3D movies, employing more than a dozen commercial processes, were shown on American screens. And, as with earlier innovations in photography and cinema, amateurs rapidly began to experiment with the new techniques.

Just as printing processes for photographs had contributed to advertising and supporting educational uses of stereo views, motion pictures again provided an impetus to reconsider the older technology. 3-D movies consolidated popular interest in three-dimensional entertainment, and made stereoscopy for adults briefly acceptable again. Zealous promoters could claim that stereoscopic cinema was an inevitable technology that satisfied not just cultural, but universal human, needs. One paper published at the height of the stereo boom outlined therapeutic benefits from viewing stereoscopic motion pictures by its potent stimulation of good binocular vision (Sherman, 1953).

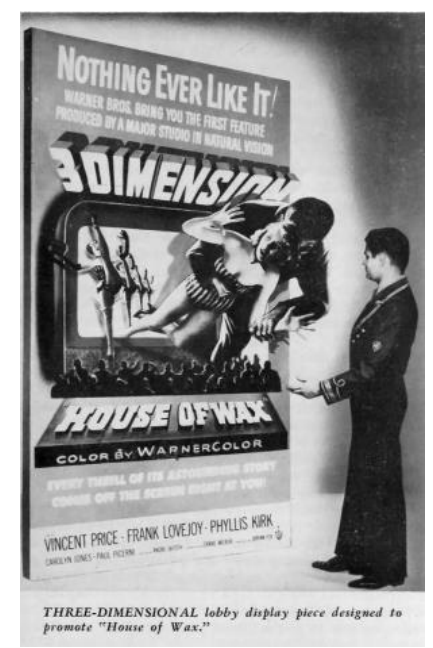

[Figure 6: Hollywood campaign for ‘3-D’ cinema, 1953]

The cinematic processes, alternately dubbed '3-D', 'Tri-Dee', 'Future Dimension', 'Tru-Stereo' or 'Natural Vision' by their various adopters, shaped the content to the technology and its potential for shock. Where widescreen films sought to awe viewers with sublime airborne travelogues and 'pictorial spectacles - without any attempt at story-telling', as a New York Times reviewer put it, 3-D movies tried to surprise and jolt their audiences. The shock could come from the plots, but even more powerfully from the moving objects that seemed to travel up to, or beyond, the viewers' seats. Many mirrored Bwana Devil, which featured man-eating (and leaping) lions and the near-tactile experience of romantic 
interludes: House of Wax contrasted the thrill of a three-dimensional fight with a comically deep PingPong game; and Dial $M$ for Murder had audiences avoiding a lunging hand. All of them sought to disorient and involve their viewers in ways that wide-screen motion pictures and stereoscopes could not.

Yet the fashion for 3-D movies faltered as audiences first experienced, and then rapidly acclimatized to, the novel visual spectacles. The peak in 1953 was followed by only two releases in 1956. Subsequent booms, about a generation apart, were more modest. The sophisticated widescreen and three-dimensional systems were invariably simplified to improve operation, reliability and profits. In each case, what could be called 'spectacle fatigue' quickly overcame audiences.

\section{Conclusion}

The environment for 3-D imaging from the 1960s, then, was conditioned by the events of the previous century. A wide variety of technologies had trained experts and conditioned audiences to refine their visual tastes and to enjoy, and expect, new forms of visual surprise. Awe-inspiring scenes, unexpected motion and the surprise of colour vied successively for attention, but the imaging of visual depth repeatedly attracted waves of viewers. Viewed from this perspective, the popularization of holograms looks familiar. Its promotion between 1964 and the early 1970s focused on the bewildering aspects that unsettled audiences: reliance on a mysteriously speckly laser beam; the immaterial image hanging in space; the hologram's ability to generate the appearance of solidity from a featureless flat plate; and, its ability to reveal mysterious scenes in impossible spaces. These compelling magicians' tricks, much like the stereoscopes that so fascinated Victorians, updated the experience for new, more discerning, audiences.

Subsequent holograms mixed some of those earlier technologies back in. The few seconds of motion created by integral holograms made the experience of viewing them much like the earlier zoetrope, but augmented by the sense of image depth. Holographic portraits were startlingly -and even uncomfortably - lifelike, producing a response from 1980s audiences probably similar to those of the 1850s seeing their first framed family photograph. The intricacy, shimmering colour and changing imagery of the first hologram identity cards entranced their first viewers as Victorian optical toys had done, but with far more sophisticated properties to discover. Each of these experiences separated by time and space was, at least for awhile, exciting, novel and precisely suited to extend the visual grammar of the times.

This examination of imaging technologies suggests that 3-D imaging is a perennial human fascination, but that its requirements vary with cultural context. An awareness of this wider environment seems crucial for twenty-first century imaging research, technological innovation, business launches and corporate investment. Keeping the visual experience fresh and perpetually exciting appears a necessary consideration. Since stereoscopy became culturally important in the 1850s, successive 3-D imaging technologies have impressed their publics either by being technologically advanced, or alternatively by being unexpected, intriguing or surprising. Three-dimensional imaging, like other forms of magic and art, repeatedly adapts itself to the cultural environments that it inhabits.

\section{References}

Bak, Meredith A. (2012). 'Democracy and discipline: Object lessons and the stereoscope in American education, 1870-1920’, Early Popular Visual Culture 10, 147-67.

Crary, Jonathan (1990). Techniques of the Observer: On Vision and Modernity in the Nineteenth Century. Cambridge, MA: MIT Press. 
David White Co. (1950), 'People who know picture-taking and picture-making prefer the Stereo Realist', Popular Photography 26 (1), 12.

Earl, Edward W., ed. (1979). Points of View: The Stereograph in America - A Cultural History. New York: Visual Studies Workshop Press.

Good, J. Paul (1920). 'The scope and outlook of visual education', School Science and Mathematics 20, 82-7, quotation p. 483.

Holmes, Oliver Wendell (1859). 'The stereoscope and the stereograph', The Atlantic Monthly, 1 June 1859.

Johnston, Sean F. (2001). A History of Light and Colour Measurement: Science in the Shadows. New York: Taylor and Francis.

Johnston, Sean F. (2006). Holographic Visions: A History of New Science. Oxford: Oxford University Press.

Johnston, Sean F. (2015, forthcoming). Holograms: A Cultural History. Oxford: Oxford University Press.

Keystone View Company (1942). 'The stereoscope goes to war', The Educational Screen: the Magazine Devoted Exclusively to the Visual Idea in Education 16, 275.

Korth, Fred G. (1944). 'Take it close up', Popular Mechanics, 81 (1), 118-21.

Lippmann, Gabriel (1891). 'La photographie des couleurs', Comptes Rendus de L'Academie des Sciences 112, 274-3.

Mitchell, Daniel J. (2010). 'Reflecting nature: chemistry and comprehensibility in Gabriel Lippmann's 'physical' method of photographing colours', Notes and Records of the Royal Society, 64, 319-37.

Nye, David E. (1994). American Technological Sublime. Cambridge, Mass.: MIT Press.

Phillips, David (1996). Art for Industry's Sake: Halftone Technology, Mass Photography, and the Social Transformation of American Print Culture 1880-1920. PhD thesis, Yale University.

Pihlainen, Kalle (2012). 'Cultural history and the entertainment age', Cultural History 1 (2012): 168-79.

Rowlands, John J. and J. Rhyne Killian Jr (1937). 'Seeing solid: the third dimension at work and play', Technology Review 39 (5), 191-5 and editorial p. 182.

Sawyer's Inc (1949). 'Sell your products with View-Master', Business Screen 10, 8.

Sherman, Reuel A. (1953). 'Benefits to vision through stereoscopic films', Journal of the Society of Motion Picture and Television Engineers 61, 295-308.

Tupitsyn, Margarita (1996). The Soviet Photograph, 1924-1937. New Haven CT: Yale University Press.

Twist, Stanley H. (1912). 'The picture of the future: a reverie', New York Clipper, 17 Aug 1912, 7.

Uncredited photographer (1937). 'Cover: Simultaneous calculator', The Technology Review 39 (3): 1.

Uncredited photographyer (1940). 'Unusual photos made with camera mirrors', Popular Mechanics, 74 (3), 406.

Uncredited photographer (1947). 'Cover', Discovery: The Magazine of Scientific Progress 8 (11): 1. 